\title{
Evaluating the Conservation Efforts of Multi-Projects Using Remote Sensing and Light Use Efficiency Model: A Case of Nyungwe Forest National Park, Rwanda
}

\section{Evariste Rutebuka1,2, Lixiao Zhang ${ }^{1 *}$, Ernest Frimpong Asamoah1,3, Emmanuel Rukundo1, Apollinaire William4}

\author{
${ }^{1}$ State Key Joint Laboratory of Environmental Simulation and Pollution Control, School of Environment, \\ Beijing Normal University, Beijing, China \\ ${ }^{2}$ Environmental Department, Institute of Life and Earth Sciences, Pan-African University (PAULESI) and \\ University of Ibadan, Ibadan, Nigeria \\ ${ }^{3}$ Department of Land Reclamation and Rehabilitation, Faculty of Forest Resources Technology, Kwame \\ Nkrumah University of Science and Technology, Kumasi, Ghana \\ ${ }^{4}$ The Nature Conservancy, Africa Region, Arusha, Tanzania \\ Email: *13868188403@139.com
}

How to cite this paper: Rutebuka, E., Zhang, L. X., Asamoah, E. F., Rukundo, E., \& William, A. (2018). Evaluating the Conservation Efforts of Multi-Projects Using Remote Sensing and Light Use Efficiency Model: A Case of Nyungwe Forest National Park, Rwanda. Open Journal of Forestry, 8 , 68-86.

https://doi.org/10.4236/ojf.2018.81006

Received: September 29, 2017

Accepted: January 7, 2018

Published: January 10, 2018

Copyright $\odot 2018$ by authors and Scientific Research Publishing Inc. This work is licensed under the Creative Commons Attribution International License (CC BY 4.0).

http://creativecommons.org/licenses/by/4.0/ (c) () Open Access

\begin{abstract}
This paper investigates the effectiveness of conservation efforts in the Nyungwe Forest National Park (Nyungwe). The forest is one of the six key landscapes identified for conservation in the Albertine Rift because it hosts many threatened species. As such, a number of different stakeholders have been involved in its conservation since 1987; yet, studies that emphasize and evaluate the success of these conservation efforts are limited. We combined a rapid and relatively low cost remotely-sensed data and the Light Use Efficiency model to generate forest conservation indicators such as NDVI, forest canopy Net Primary Productivity and carbon sequestered from 1986 to 2010. The influence of topographic and climatic factors on these indicators was examined. The supervised classifier was used to catalogue the area into Forest, Wetland, and Bareland. The forest was the major category (above 90\%) of Nyungwe relative to wetland and bareland. Based on degradation intensity, two distinctive periods were realised; the first period spans 8 years (1986-1994) whereas the second spans 16 years (1994-2010). The former degradation intensity period is 10 times higher than the latter period. Although the size of forest recovered up to $90 \%$, the daily NPP and carbon sequestration capacity decreased by $37.1 \%$ (i.e. NPP $6.5 \mathrm{Mg}$ tons in 1986 to $4.1 \mathrm{Mg}$ tons in 2010). Areas of the forest that are physically constrained
\end{abstract}


(high altitude) had a higher degradation. Guided by our indicators, there is an overall success in conservation efforts, but efforts were mostly concentrated in accessible areas. Therefore, conservation efforts that aim to respond to degradation of the inaccessible areas of the forest should be stressed in the management plan of the park.

\section{Keywords}

Conservation Efforts, Forest Canopy Cover, Light Use Efficiency Model, Remote Sensing, Nyungwe, Rwanda

\section{Introduction}

It is essential to understand whether conservation efforts are yielding the desired effects (Washington et al., 2015). Nevertheless, most organisations struggle to implement appropriate, and/or effective monitoring and evaluation schemes (Kapos et al., 2008). Where some efforts exist, there is uncertainty about how to determine the right level of investment and to choose the correct tools to measure the conservation success (Wilder \& Walpole, 2008). Kapos et al. (2008) iterate that resources for conservation are still inadequate due to the scale of the problem. Therefore, conservationists are very limited to assist in the protection of protected areas (PAs) due to limited funds for research and other related conservation projects in spite of the conservation efforts that have taken place in the last 50 years in East Africa (Adams, 2016; Myers et al., 2000).

Regardless of uncertainties surrounding the tools and methods for evaluating conservation efforts, there are several methods used to investigate the effectiveness of conservation projects. It includes critical stories of change (Okwaare \& Hargreaves, 2009), systematisation (Selener et al., 1996), outcome mapping (Davies, 2012; Earl et al., 2001), etc. These methods have been replicated across different sites and have demonstrated progress within a conceptual model but they are time-consuming, expensive, and unsuitable for providing in-depth understanding of an issue (Wilder \& Walpole, 2008). Nevertheless, success stories of the "Most Significant Change (MSC)" method have been reported in Bangladesh, Ghana, Vietnam and in Mekong Delta for participatory film making (Wilder \& Walpole, 2008). Regardless of its strength, it shares a common weakness with the previous methods since it requires a considerable investment of time and high cost. Most of these methods measure effectiveness at either a project level (Kapos et al., 2008) or organisational level, and some at species level as an indicator of conservation success (Washington et al., 2015). Because they are project-specific, they are less likely to provide an accurate measure of its success or monitor time-series habitat change because no post-implementation monitoring plan is often instituted (Kapos et al., 2008). In addition, the Cambridge Conservation Forum (CCF) has developed a conceptual framework and a practical scorecard for evaluating major conservation activities but this method requires much time and cost and 
also needs many inputs such as past project reports, previous studies results and others to be successfully applied. Therefore, Geographic Information System (GIS) combined with Remote Sensing (RS) and Light Use Efficiency, hereafter known as Combinatory Tool Method (CTM) was proposed to overcome the time consuming, high cost, and bias-prone methods.

Previously, the GIS and RS have been applied to ascertain forest habitat status (Dewan \& Yamaguchi, 2009; Li et al., 2012; Reusing, 2000). The LUE theory was introduced by Monteith (1972) and later developed for further application in Remote Sensing technology. It has been noted as an effective method to monitor global Net Primary Productivity (NPP) and sequestrated carbon using satellite-borne sensors (Myneni \& Williams, 1994; Turner et al., 2002). The LUE describes how efficient vegetation fixes solar energy. Thus, the LUE combined with remote sensing data can model the vegetation productivity on a small or large scale (Li et al., 2012).

Determining the extent and nature of degradation invariably determines the status of its hosts. It then defines the impact of combined stakeholders' conservation efforts over a long period. Thus, CTM can easily tackle and reduce the burden of research paucity due to financial constraints in Africa, at the same time measuring the impacts of different conservation efforts invested by different stakeholders in either conserving single species, multiple species or habitat. The CTM can measure spatiotemporal change indicators and the degree of indicators degradation to the associate's factors like slope, altitude and climatic (Myneni \& Williams, 1994; Turner et al., 2002).

In this study, we evaluate the status of the Nyungwe forest National Park by using the CTM. The Rwanda's Nyungwe National Park is one of the six key forest habitat identified for conservation in the Albertine Rift (AR) being a host for many threatened species (Masozera, 2002; Seimon, 2012). The Nyungwe National Park herein called Nyungweto avoid acronym confusion between Nyungwe National Park (NNP) and Net Primary Productivity (NPP). Nyungwe has been experiencing much conservation efforts since the Wildlife Conservation Society (WCS) joined the Tourism and Conservation Department of the Rwanda Development Board (RDB) in 1987. But these conservation efforts have been continuously undermined by the burning of large areas in 1997 (Barnett \& Dardis, 2011) and an increased rate of tree cutting 2010 (Mulindahabi et al., 2011). On another hand, Nyungwe's conservation efforts were concentrated on community-based conservation projects while research was more concentrated on phenology and ethology of that threatened fauna and flora and species inventory and discovery along with biodiversity surveys studies (Fashing et al., 2007; Fischer et al., 2003; Kaplin, 2001; Rutebuka et al., 2012). To the best of our knowledge, no study has tempted to assess its canopy cover over a period.

The main study objective was to investigate the combined conservation efforts success from different stakeholder of the Nyungwe. The specific objectives are to 1) use Normalized Difference Vegetation Index (NDVI) as an indicator to measure the intensity of degradation of Nyungwe from 1986 to 2010,2) explore the cor- 
relation of slope and altitude with degradation, and 3) estimate the canopy Net Primary Productivity and sequestered carbon by using the Light Use Efficiency (LUE) model.

\section{Material and Methods}

\subsection{Description of Study Area}

Nyungwe is located in south-western part of Rwanda between latitude $2^{\circ} 15^{\prime}$ and $2^{\circ} 55^{\prime}$ south and longitude $29^{\circ} 00^{\prime}$ and $29^{\circ} 30^{\prime}$ east. Its altitude ranges from $1600 \mathrm{~m}$ and $2950 \mathrm{~m}$ a.s.l (Plumptre et al., 2004) (Figure 1). It was established in 1903 as a forest reserve by the colonial administration, from 1958 to 1973 Nyungwe has been downsized by over $150 \mathrm{~km}^{2}$ due to fires, wood cutting, poaching, and small-scale agriculture (Alec, 2012). A buffer zone was established in 1984 to protect the park and its ecosystems from resource exploitation and reduce contact between the park's wildlife and the local population (Alec, 2012). In 1988, the Rwandan Office of Tourism and National Parks (ORTPN) was given the mandate to enforce conservation regulations in the forest including efforts to control illegal mining, hunting and forest clearing (Masozera, 2002).

This protection status was upgraded to national park status in 2005. Since then, Nyungwe is the largest Afromontane protected area in Rwanda with $1015 \mathrm{~km}^{2}$ without counting Cyamudongo and Gisakura forest according to the Rwandan law establishing Nyungwe National Park in 2005. The Nyungwe is one of the most significant rainforests in Africa because it is one of the few large surviving forests remaining between the altitudes of 1600 - $2900 \mathrm{~m}$ (Plumptre et al., 2004). When Nyungwe is considered together with the contiguous Kibira National Park in Burundi, they form one of the largest protected tropical mountain forests in Africa. Nyungwe is also recognized as a site of global importance for its biodiversity and endemism values, which are among the highest within the biologically rich Albertine Rift eco-region (Seimon, 2012). The climate of Nyungwe is typical of a tropical montane forest and is characterized by the bimodal regime with very small thermal seasonality and a long-wet season extending from September to May and much drier conditions during the mid-year months. The major dry season occurs between July and August and minor dry season takes place between December and January (Seimon, 2012).

\subsection{Methods}

\subsubsection{Data Acquisition}

Freely available dry season Landsat Thematic Mapper images were downloaded from the U.S. Geological Survey Global Visualisation Viewer (USGS, 2016) along with Rwanda Digital Elevation Model (DEM) for this study. Three criteria were taken into consideration i.e. cloud cover less than 5\%, strip lines free and image acquisition date varies between July to August (dry season) (Table 1) to make

sure that the results are of high quality of image and season climatic conditions consistencies. 


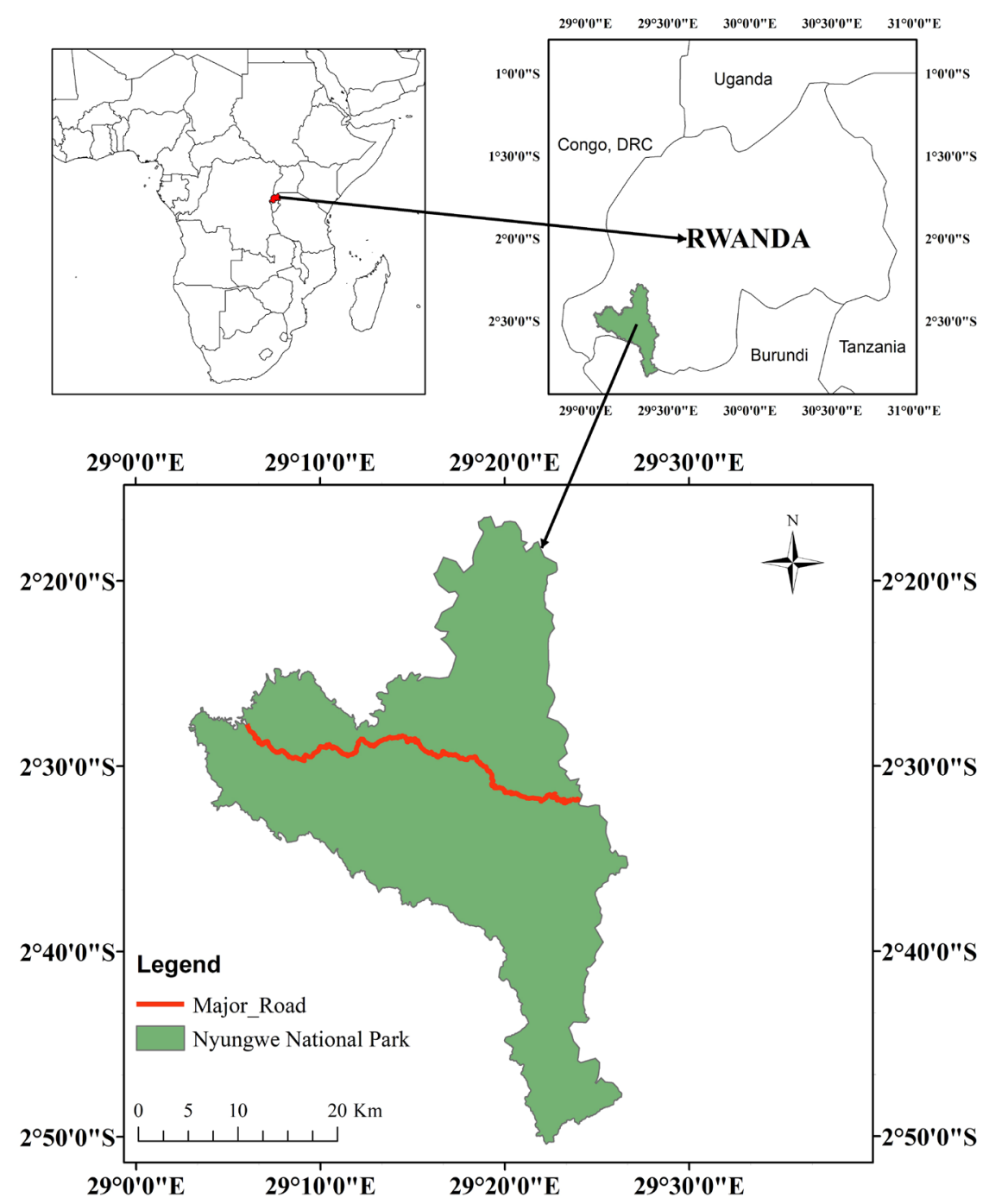

Figure 1. Location of Nyungwe National Park (Nyungwe).

Table 1. Remote sensed data used for analysis of Nyungwe cover changes.

\begin{tabular}{ccccccc}
\hline Image & Path/Row & Acquisition Date & Season & $\begin{array}{c}\text { Spatial } \\
\text { Resolution }\end{array}$ & $\begin{array}{c}\text { Image } \\
\text { Quality }\end{array}$ & $\begin{array}{c}\text { Cloud Cover } \\
\text { (C.C) }\end{array}$ \\
\hline Landsat TM 5 & $173 / 062$ & July 19, 1986 & Dry & $30 \mathrm{~m}$ & 9 & $0 \%$ \\
Landsat TM 4 & $173 / 062$ & August 4, 1989 & Dry & $30 \mathrm{~m}$ & 7 & $0 \%$ \\
Landsat TM 5 & $173 / 062$ & July 25, 1994 & Dry & $30 \mathrm{~m}$ & 9 & $3 \%$ \\
Landsat TM 5 & $173 / 062$ & August 22, 2010 & Dry & $30 \mathrm{~m}$ & 9 & $0 \%$ \\
Rwanda DEM & \multicolumn{2}{c}{ From NUR CGIS_Rwanda } & $10 \mathrm{~m}$ & - & - \\
\hline
\end{tabular}

The interval between series was not regular due to the cloud cover interference and seasons. These criteria have led to time series limit to 2010. The only images of 1986, 1989, 1994 and 2010 fulfil the criteria and were used in this study. The two meteorological stations have been identified in Nyungwe for daily recording of solar radiation, temperature, relative humidity and precipitation 
from the National Centres for Environmental Prediction (NCEP) and Climate Forecast System Reanalysis (CFSR) (NCEP, 2016). Monthly averages of the meteorological data were based on the acquired date of satellite imagery to express light use efficiency of Nyungwe. The collected data were analysed through designed framework Figure 2. Technical Framework for coverage change detection, NPP and DEM relationship.

\subsubsection{Data Processing}

The Environment for Visualizing Images (ENVI) image processing software was applied to the different time series Landsat images for accurate extraction and change detection analysis. First, the Dark Object Subtraction (DOS) was applied before atmospheric correction for converting digital numbers to at-satellite reflectance. The reason underneath is a conversion of digital numbers at satellite reflectance the fact that the dates of acquisition, sun azimuth and sun elevation angle varied. The temporal differences in sensor calibration and in environmental factors between the images acquired were also corrected. The digital numbers (DNs) were converted at satellite reflectance values for targeted bands (Huang et al., 2001; Myeong et al., 2006). Radiance was calculated from DN as follow in the Equation (1).

$$
L_{\lambda}=\left(D N_{\lambda} \operatorname{gain}_{\lambda}\right)+\text { bias }_{\lambda}
$$

where; $L$ is radiance; $\lambda$ is the spectral band; the gain is the spectral band gain and bias is the spectral band offset. Then, the signal in each band and at each pixel was converted to in-band planetary albedo using the following Equation (2).

$$
\rho_{\lambda} \frac{\pi L_{\lambda} d^{2}}{E_{\text {sun } \lambda} \cos (\theta)}
$$

where; $\rho$ is the unitless planetary reflectance; $d$ is the Earth-Sun distance; $E_{\text {sun }}$ is the solar atmospheric irradiance; and $\theta$ is solar zenith angle in degree (Myeong et al., 2006).

After radiometric correction, band masking and registration to Nyungwe (WGS 84/UTM zone 35S) and bands stacking procedure were performed. The classification was based on ground knowledge of features such as wetlands and infrastructure e.g., roads and buildings. The main road that passes through the Nyungwe, Kitabi and Uwinka buildings, represented bareland during the selection of Regions of Interest (ROI) for classification. In addition, the Kamiranzovu wetland patches were selected as ROI to present wetland, and the main forestland class ROI was easily identified and selected since is it the main coverage of Nyungwe. The selected ROIs were used as training data for supervised maximum likelihood classification. The images were classified into three land cover types namely wetland, forestland, and bareland using ENVI (v4.7) image processing. Before classification, we evaluated the ROIs to check the band separability. Band five (5) and six (6) were a good indicator of bareland, road and water body. Zhao, Chen and Area (2005) introduced the bareness index for quick mapping of bare areas 


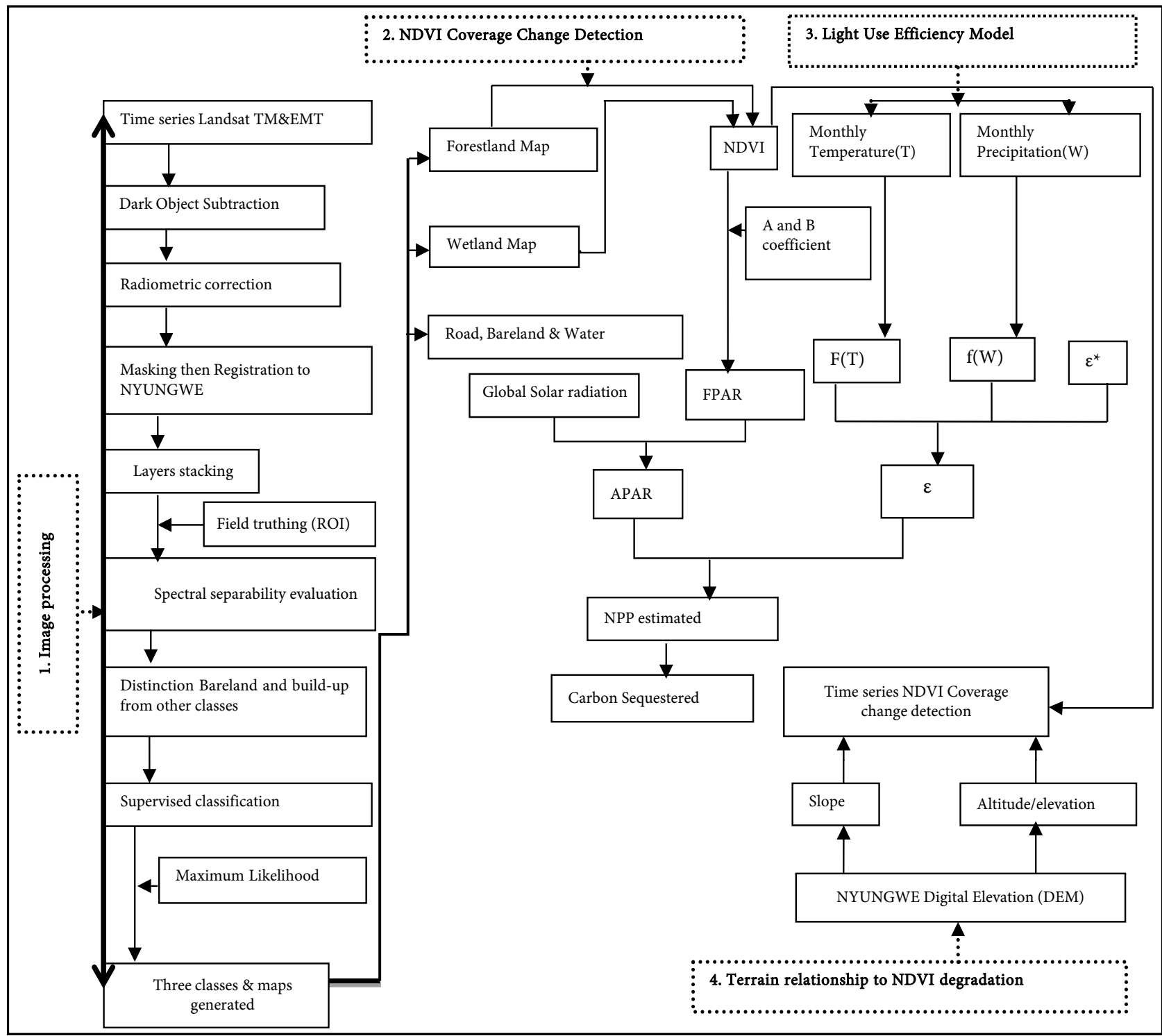

Figure 2. Technical framework for coverage change detection, NPP and DEM relationship.

from Landsat TM and ETM data. The relation is stated as Equation (3) NDBare is always positive for bareland (Uddin et al., 2010).

$$
\text { NDBare }=\frac{\text { Band } 5-\text { Band } 6}{\text { Band } 5+\text { Band } 6}
$$

Wetland reflectance value was higher than forestland reflectance for band one, two and three. After the band separability analysis for each ROI, we run a supervised classification with maximum likelihood.

Though the ROI were chosen based on our best knowledge of study site, we conducted classification accuracy assessment and validation after supervised classification. Each class was examined against 150, 80 and 50 points for forestland, wetland and bareland classes, respectively. The points were collected in the field by means of global position systems (GPS) based on the rule of thumb of 50 points 
minimum per class (Congalton \& Green, 2008) then evaluated using error matrix of user's and producer's accuracy, overall accuracy and the Kappa coefficient. Since the ground truth GPS points were too younger than Landsat images of 1986 to 2010, GPS points were collected guided by indigenous knowledge and long existing key features like main road and buildings, Kamiranzovu wetland and non-disturbed forest patches.

\subsubsection{Change Detection}

Change detection is defined as a process of identifying fluctuations in the state of an object or phenomenon by observing images at different times (Singh, 1989). Change detection studies seek to know 1) pattern of forest cover change, 2) processes of forest cover change (Forkuo \& Frimpong, 2012). Evaluating coverage change using RS and GIS technologies has been found to be effective and efficient by many researchers (Dewan \& Yamaguchi, 2009; Fichera et al., 2012; Myeong et al., 2006; Reusing, 2000). Change detection stage was proceeded based on the Normalized Difference Vegetation Index (NDVI) generated raster to the fact that NDVI is the best index indicating greenness or healthy vegetation than other indices (Bannari et al., 1995; Myeong et al., 2006). NDVI is calculated in Equation (4).

$$
N D V I=\frac{(N I R-R)}{(N I R+R)}
$$

where: Near-Infra-Red (NIR) is the spectral reflectance measurements acquired in the near-infrared region also known as band four and the Red band (R) is the spectral reflectance measurements acquired in the red region known as band three (Woodcock et al., 2001).

The raster calculator was used and subtracted the 1986 NDVI image (raster) from the 2010 image and performed other time series change detection analysis. The pixel with negative value result indicates degraded areas or implies that the health vegetation of older image was better than the recent image; closest result value to zero or zero indicates neutral or non-degraded areas while positive result value presents upgraded areas. To evaluate altitudinal correlation with degradation, Digital Elevation Model (DEM) terrain of Rwanda of $10 \mathrm{~m}$ pixel size was re-sampled to $30 \mathrm{~m}$ pixel size using the nearest neighbour method to correspond $30 \mathrm{~m}$ pixel resolution of Landsat image.

\subsubsection{Light Use Efficiency (LUE) Model}

The LUE theory introduced by Monteith (1972) has been extensively applied because of the simplicity of its mechanisms, and the fact that it requires fewer physiological and ecological parameters, and can be easily combined with the remote-sensed data ( $\mathrm{Li}$ et al., 2012). LUE is considered as constant for certain vegetation types or even entire eco-regions (Myneni \& Williams, 1994; Turner et al., 2002). It is also an index to describe the efficiency of vegetation for fixing solar energy for NPP. NPP is defined as the net flux of carbon from the atmosphere into green plants per unit time. It refers to a rate process, i.e., the amount 
of vegetable matter produced per day, week, or year (Gao et al., 2013).

For an area, the NPP $\left(\mathrm{gC} \cdot \mathrm{m}^{-2}\right)$ equals an Amount of Photosynthetically Active Radiation (APAR) absorbed by green vegetation expressed in $\mathrm{MJ} \cdot \mathrm{m}^{-2}$ multiplied by the actual light use efficiency $(\varepsilon)$ expressed in $\mathrm{gC} \cdot \mathrm{MJ}^{-1}$. The actual light use efficiency is the radiation that is converted to plant biomass increment ( $\mathrm{Li}$ et al., 2012; Turner et al., 2002). NPP is calculated as follows in Equation (5):

$$
N P P_{x, t}=A P A R_{x, t} \times \varepsilon_{(x, t)}
$$

where: $A P A R$ is the fraction of Photosynthetically Active Radiation (fPAR); it can be calculated as half of the total solar surface radiation (SOL) which is expressed $\mathrm{MJ} \cdot \mathrm{m}^{-2}$. SOL $(x, t)$ refers to the global solar radiation of pixel $\mathrm{x}$ during the time $t$. The fPAR is the fraction of the incoming PAR intercepted by green vegetation, and the factor of 0.5 was used because approximately half of the incoming solar radiation is in the PAR waveband $(0.4-0.7 \mu \mathrm{m})$ (Potter et al., 1993) Equation (6).

$$
A P A R_{x, t}=S O L_{x, t} \times f P A R_{(x, t)} \times 0.5
$$

The $f P A R$ algorithms are the most important component of this model. The strong relationship between the normalised difference vegetation index (NDVI) and light absorbed by green vegetation make models based on LUE attractive in the remote sensing context (Sims et al., 2006). Daniel Sims found a linear relationship between $f P A R$ and NDVI for a large set of different vegetation and $a$ and $b$ are empirical constants for that relationship (Li et al., 2012) Equation (7)

$$
f P A R=1.24 * N D V I-0.168
$$

The plants used to develop this relationship included species common at sky oaks as well as a wide range of other plant species and functional types (including annuals, vines, deciduous and evergreen shrubs and trees, 16 species in all).

According to Potter et al. (1993), vegetation has maximum light use efficiency $\left(\varepsilon^{*}\right)$ of $0.389 \mathrm{gC} \cdot \mathrm{MJ}^{-1}$ in an ideal condition, but the actual light use efficiency $(\varepsilon)$ is affected by temperature and water. Therefore, $\varepsilon$ can be described as a function of temperature and water stress (Field et al., 1995; Li et al., 2012; Potter et al., 1993; Turner et al., 2002; Wenquan et al., 2006). The relationship that allows effects of temperature and water stress on $\varepsilon^{*}$ is expressed in Equation (8).

$$
\varepsilon_{(x, t)}=T_{(\varepsilon 1)}(x, t) * T_{(\varepsilon 2)}(x, t) * W_{(\varepsilon)}(x, t) * \varepsilon^{*}
$$

where: $T_{(\varepsilon 1)}$ and $T_{(\varepsilon 2)}$ account for effects of temperature stress, $W_{(\varepsilon)}$ accounts for effects of water stress, $\varepsilon$ is the light-use efficiency $\left(\mathrm{gC} \cdot \mathrm{MJ}^{-1}\right)$ and $\varepsilon^{*}$ is the maximum light use efficiency. More information about the light use efficiency, equations and procedures please refer to (Potter et al., 1993). Photosynthetic optimum temperature is important to run the Equation (8), therefore, it has been extracted from (Mau, 2015; Potter et al., 1993; Vårhammar et al., 2015).

To estimate carbon sequestration, the NPP was multiplied by $44 / 12$ (3.67) to convert it into $\mathrm{CO}_{2}$ removal from the atmosphere (Lal \& Singh, 2000; Li et al., 2012). 


\section{Results}

\subsection{Validation Analysis}

The accuracy assessment performed based on ground truth information showed that all classes scored higher than 70\% of Kappa coefficient with an overall accuracy higher than $80 \%$ in each class. The lowest accuracy is observed in the 2010 image. However, the observed variation was high in bareland where the high omission and commission errors were observed.

\subsection{Cover Type Classes and NDVI Dynamics of the Study Area (1986-2010)}

The supervised maximum likelihood classification generated three distinct land cover types. The dominant cover type was forest, which covered $91 \%$ (1986) to $90 \%$ of total size park in 2010 . Wetland and bare covered $7.5 \%$ to $6.9 \%$ and $1.3 \%$ to $3 \%$ in 1986 and 2010, respectively. The size forest cover shrunk by $42 \mathrm{~km}^{2}$ from 1986 to 1994 but it recovered by $32 \mathrm{~km}^{2}$ from 1994 to 2010 . Wetland was downsized from $77 \mathrm{~km}^{2}$ in 1986 to $57 \mathrm{~km}^{2}$ in 1989 but it recovered to about 70 $\mathrm{km}^{2}$ in 2010. The dynamics of the forest was not the same as its mean NDVI. The mean NDVI decreased from 0.46 to 0.29 from 1986 to 2010, respectively. A similar trend in degradation was also observed to the wetland cover type (Figure 3 ).

\subsection{Forest Health Analysis}

The NDVI time series was used as the basis to assess forest health. The coverage change detection was calculated and categorised into three levels based on pixel values (Figure 4 and Figure 5).

The change detection process performed for 1989/1986, 1994/1986 and 2010/1986 revealed the overlapping proportion of $95 \%, 89 \%$ and $92 \%$, respectively (Figure 6). The degradation increased from $13.7 \%$ in 1989 to $84 \%$ in 1994 and $92.4 \%$ in 2010. The lowest degradation was observed from 1986 and 1989 with the highest unchanged category of $83.3 \%$. The degradation intensity of $84 \%$ observed from 1986 to 1994 was 10.5 times higher than the second period which recorded 8\% increase from 1994 to 2010 (Figure 6).

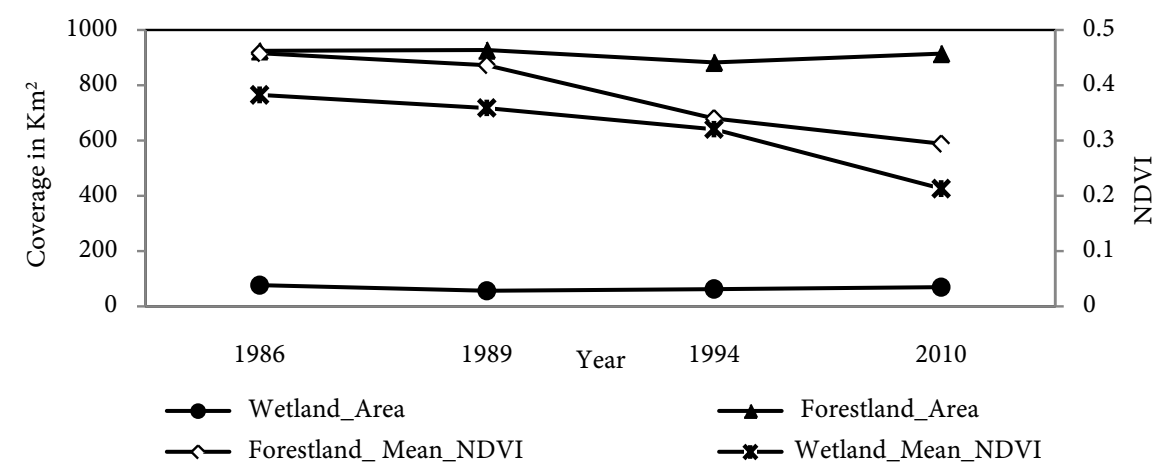

Figure 3. Forestland and wetland coverage and the mean value of NDVI. 


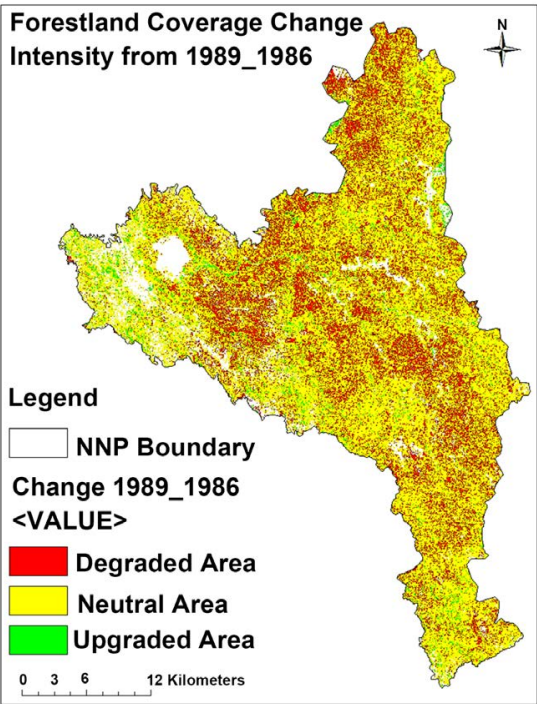

(a)

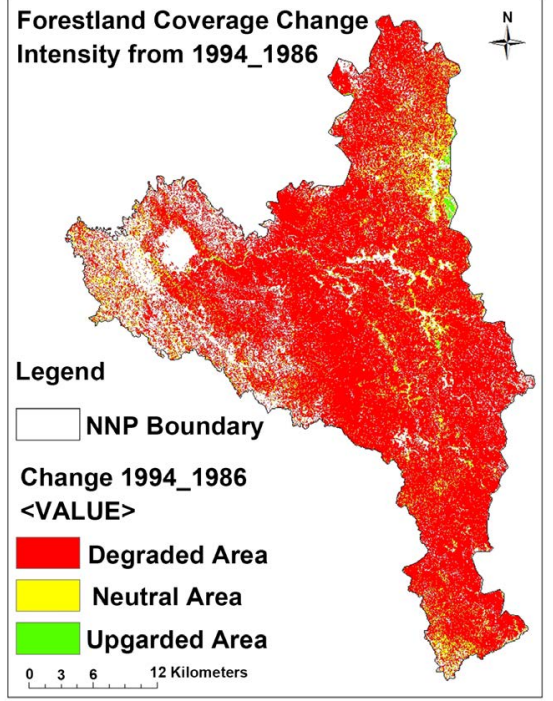

(b)

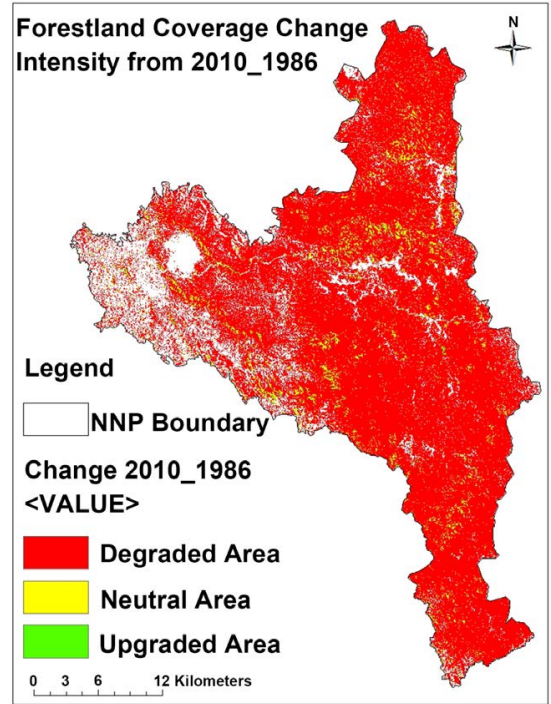

(c)

Figure 4. Forestland NDVI based change categorisation.

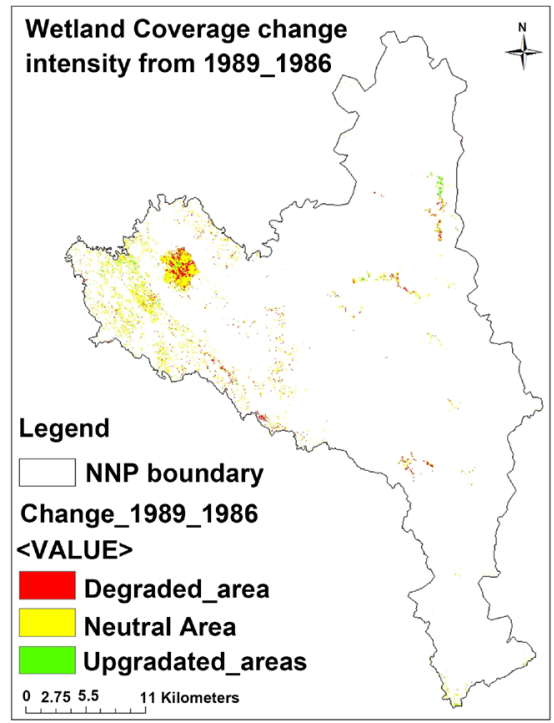

(a)

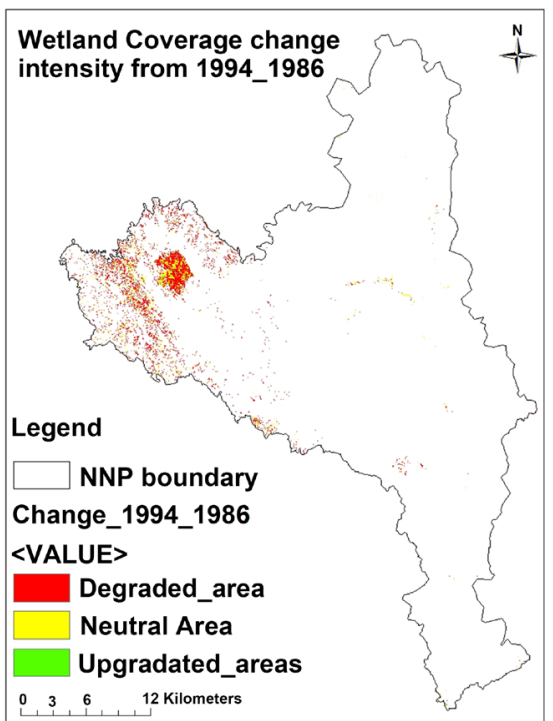

(b)

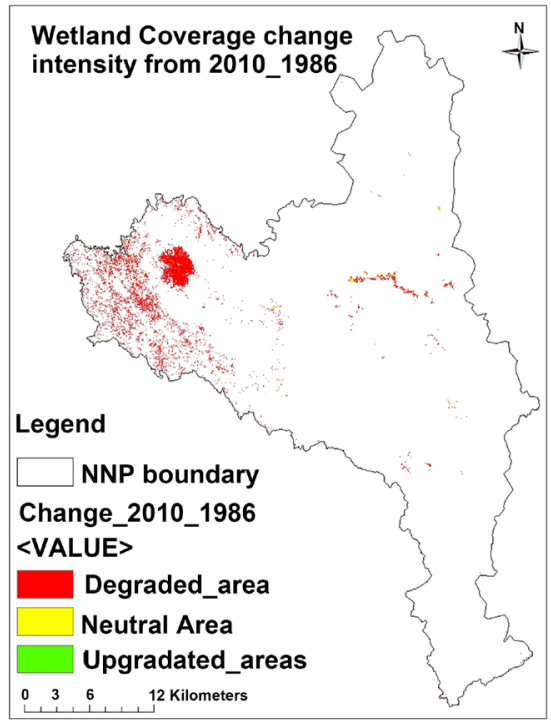

(c)

Figure 5. Wetland NDVI based change categorisation.

\subsection{Ecosystem Services: Net Primary Productivity and Carbon Sequestration}

The Light use efficiency model combines NDVI with climatic and other variables to generate a comprehensive daily canopy NPP and carbon sequestration in the dry season (Figure 7 forestland) and (Figure 8 wetland). The highest forestland daily canopy NPP was 6.5 megatons in 1986 and 23.9 megatons of carbon sequestered. The daily NPP quantity was driven by many factors including pixel NDVI, size, light intensity, temperature and water. Forestland decreased by $37.1 \%$ of its daily canopy NPP capacity from 1986 to 2010 (6.5 to 4.1 megatons). 


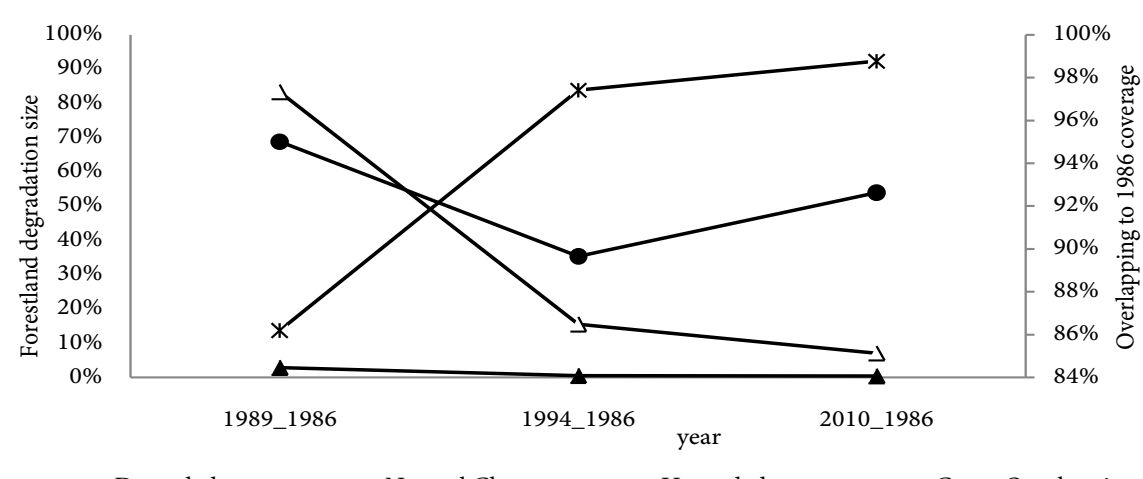

-*— Degraded areas $\longrightarrow$ Neutral Change $\longrightarrow$ Upgraded areas

Figure 6. Forestland degradation level and land-cover overlapping.

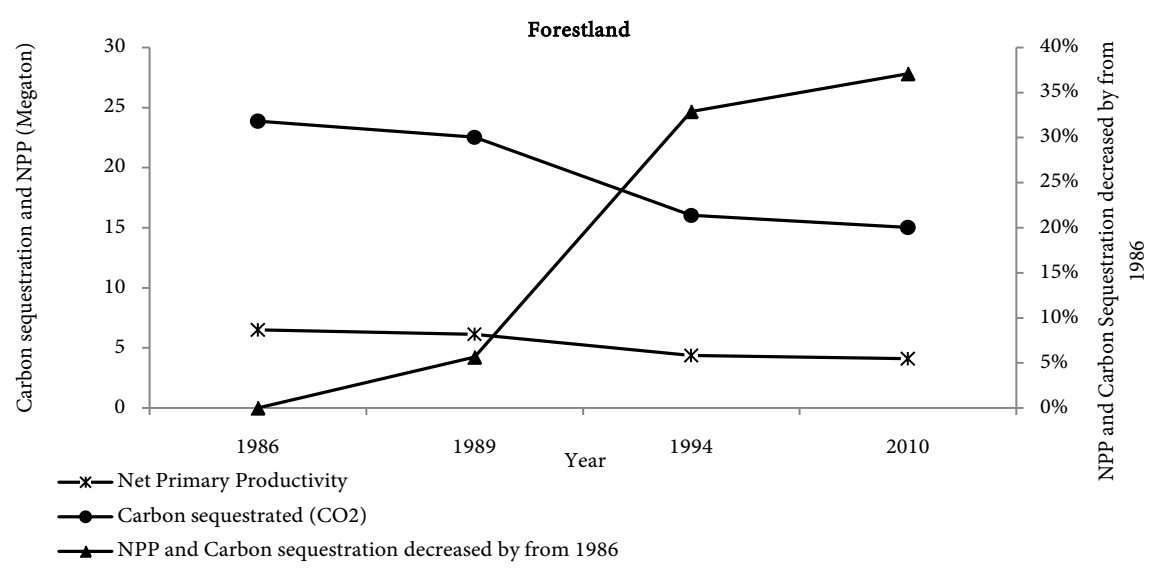

Figure 7. Forestland daily canopy NPP and carbon sequestered.

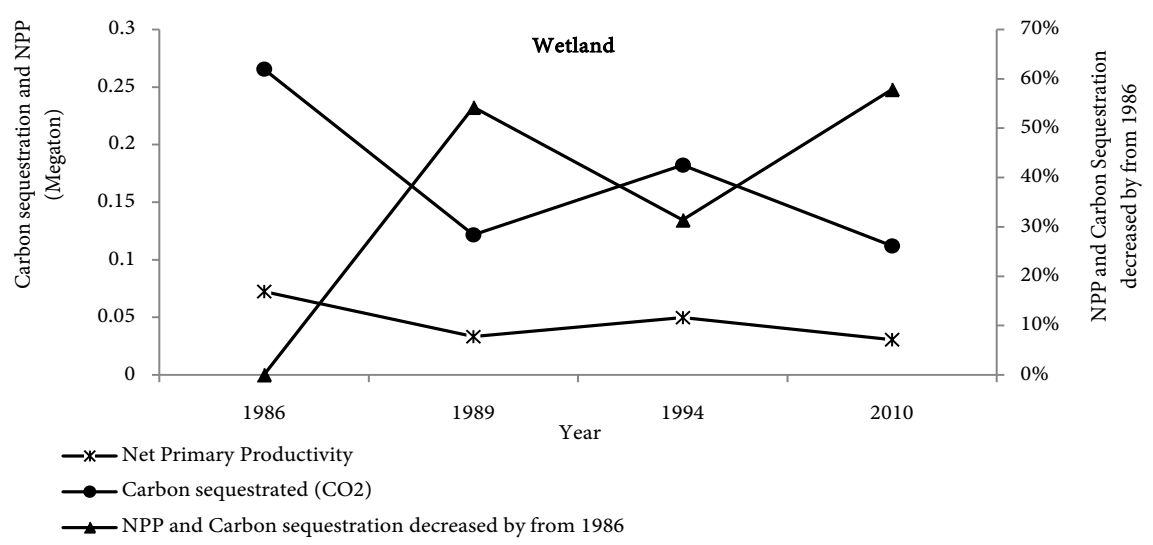

Figure 8. Wetland daily NPP and carbon sequestered.

The highest decrease or 33\% was observed only in a span of 8 years (1986 to 1994, from 6.5 to 4.3 megaton). Carbon sequestrated $\left(\mathrm{CO}_{2}\right)$ decreased from 23.9 to 15 megatons and follows the trend of NPP (Figure 7). The wetland results are presented in (Figure 8).

\subsection{Topographic Factors and Degradation of Forestland}

The degradation of natural resources is associated with many factors which in- 
clude human and natural induced factors. The degradation was significantly correlated with all of the topographic factors. The altitude analysis showed that degradation trend follows altitude linearly, the higher altitude the higher degradation with weak but significant correlation $(\mathrm{r}=-0.070, P$-value $<0.01, \mathrm{~N}=951,266$ pixels). The high concentration of degraded is observed above $2000 \mathrm{~m}$ a.s.l (Figure 9).

The statistical analysis for slope showed significant correlation $(r=0.119$, $P$-value $<0.01, \mathrm{~N}=951,266$ pixels). It indicated the low slope, high degradation; low slope areas are more likely to be degraded based on this study results (Figure 10).

\section{Discussions}

\subsection{Regional Insecurity as a Driver of Nyungwe Degradation}

The higher degradation revealed during the first half of the study period (19861994) corresponds to the period of armed insecurity started earlier 1990 until Rwanda Genocide of 1994 which led to the collapse of all undergoing projects in Nyungwe. This has affected not only human life but also wildlife. In some cases, it posits that armed conflicts may result in positive environmental impacts (e.g. vegetation and wildlife protection) when people a restricted of having access (e.g. militarised zones) (Brown et al., 2009; Dudley et al., 2002; Matthew et al., 2002; Price, 2003). However, the Rwandan case has negatively influenced the environment, its insecurity was characterised by natural resources over-exploitation and biodiversity, habitats, and wildlife degradation. The insecurity elucidated the dramatic degradation from 1989 to 1994 since refugees camps were established inside the forest and along with illegal activities including farming inside the
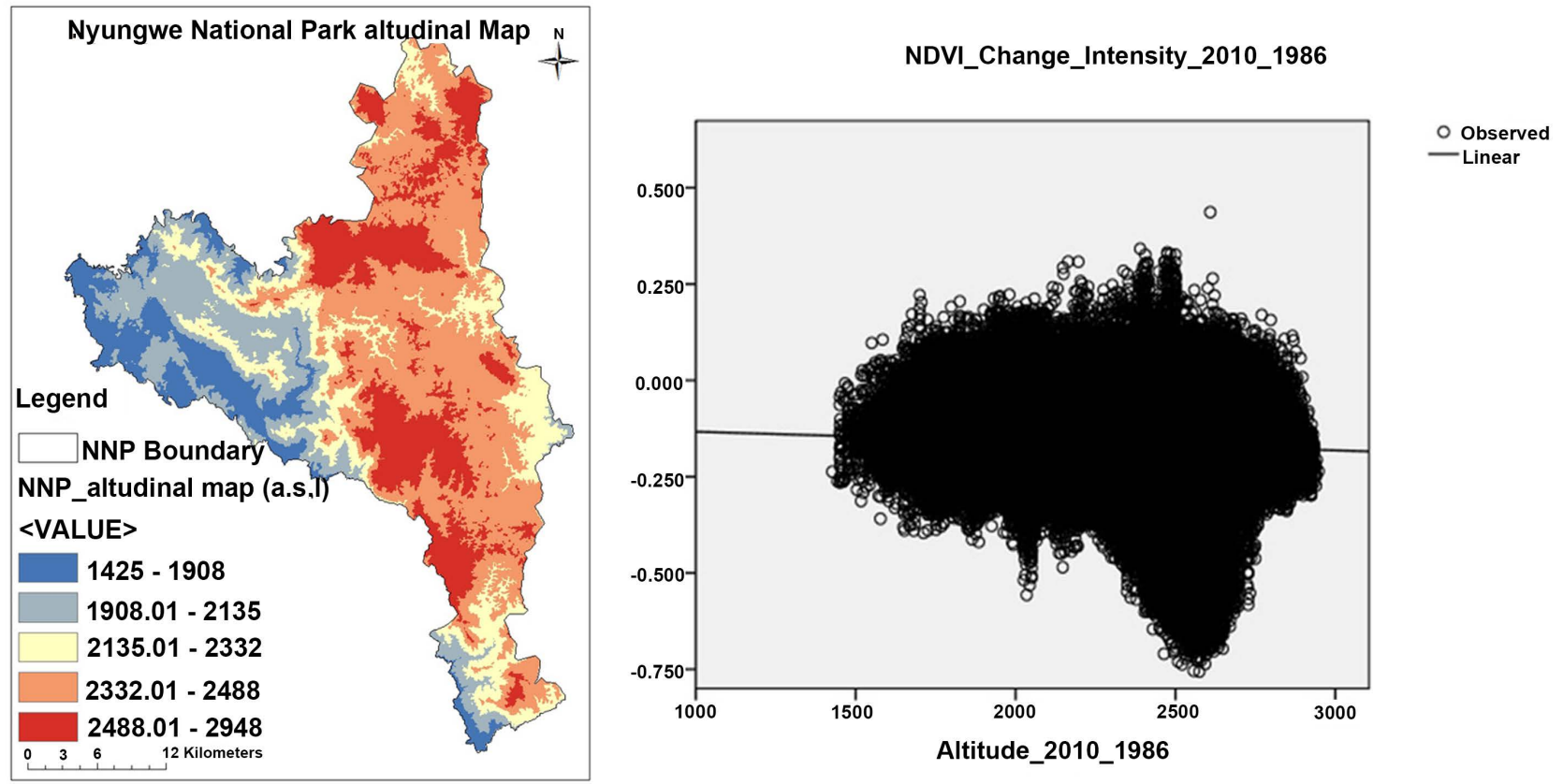

Figure 9. Altitudinal factor of Nyungwe: Altitude (X-axis) against NDVI change detection value (Y-axis). 

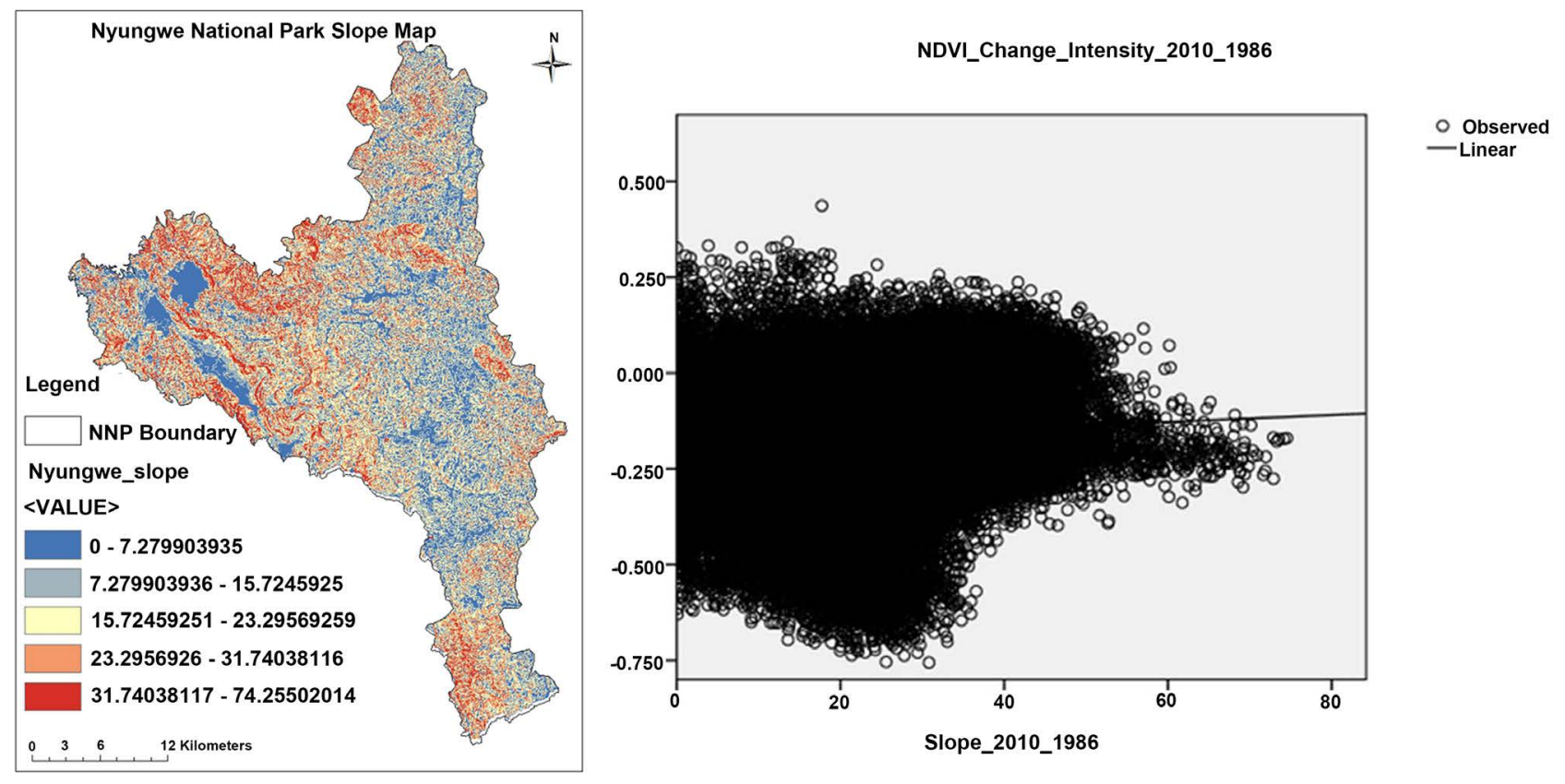

Figure 10. Slope factor of Nyungwe: Slope (X-axis) against NDVI change detection value (Y-axis).

park (Glew \& Hudson, 2007; Kanyamibwa, 1998; Webber, 2013). Among numerous issues resulted from insecurity, government and populations struggle to rebuild and recover from other critical issues than environmental considerations often do not receive immediate attention (Cowles et al., 2013; Plumptre et al., 2002; Webber, 2013). This has posed a number of critical challenges to biodiversity conservation and then contributed evidently to a continuous degradation of Nyungwe after insecurity.

\subsection{Degradation and Topographic Conditions}

The topography of an area (e.g. altitude and slope) defines the possibility of access and determines the likelihood of environmental degradation by the human population. The study showed some interesting results where the high-altitude areas (i.e. the relatively inaccessible places) were the most degraded areas. This can be attributed to the fact that park patrol team monitors the forest area close to major roads and the boundaries between local population and park (Mulindahabi \& Ntare, 2013) reports that rangers leave out the inaccessible places uncontrolled. Additionally, the Ranger Based Monitoring (RBM) system that was introduced in Nyungwe in 2003 aimed to monitor threats and key wildlife species within the park boundaries, as well as identify any trends and changes (Mulindahabi \& Ntare, 2013), may be a reason for the low degradation of the forest from 1990 to 2010. In 2010, wildfires led to the loss of about 500 hectares of the park (Mulindahabi et al., 2011).

\subsection{Climatic Envelope Influences on Nyungwe Degradation}

Climate envelope includes temperature, precipitation and solar radiation variables 
were discussed with the recent study on Nyungwe which has used Community Earth System Model (CESM) (Seimon, 2012). The model has found similar results with the present study where it has shown a broadleaf evergreen tree, broadleaf deciduous tree and carbon in leaves in the tropical area have a continuous decline from the 1970s until the range of present study time frame and after (Seimon, 2012). This reflects our results where the NPP capacity loss and NDVI degradation for Nyungwe have a continuous decline too. But temperature, precipitation and solar radiation variables used in Equation (8) for maximum light used efficiency still benefiting the flourishing of Nyungwe vegetation as long as the photosynthetic optimum temperature is not yet reached for Nyungwe (Vårhammar et al., 2015). The temperature and precipitation increase found in Seimon (2012) still an advantage to the photosynthesis. These flourishing factors of temperature and precipitation are neither explained by the present study nor by Seimon (2012) study. Therefore, the present study did not find any correlation between canopy cover degradation and climatic conditions.

\section{Conclusion}

The study assessed the forest cover changes over a period of 25 years (1994-2010) to ascertain the impacts of multiple projects that aimed to conserve the Nyungwe Park. Human-induced degradation is the most suspected threats to Nyungwe's canopy cover during the high insecurity period. The reduction of carbon sequestration potential of the forest over the period has economic implications in terms of the polluter pay protocol. Degradation intensity decreased significantly (i.e. about 10 times) after the re-opening of conservation projects after the insecurity. Both wetland and forestland classes had recovered in size toward the relative original size in observed in 1986. Thus, the study identified that security is a key for conservation success. It is evident that Nyungwe is still facing threats. However, the inaccessible places are more susceptible to high threats to these threats. Therefore, periodic monitoring and park patrols should consider these inaccessible places in their management plan. Additionally, a more specific research on climatic change impact on vegetation dynamism of this forest is highly recommended. As a good indicator of conservation efforts, the CTM method used can be used to evaluate other forests reserves and/or protected areas.

\section{Acknowledgements}

This work was supported by The National Science and Technology Major Project of the Ministry of Science and Technology of China (2017YFC0505703), WWF Prince Bernhard Scholarships for Nature Conservation 2015 and Fund for Innovative Research Group of the National Natural Science Foundation of China (Grant No. 51421065). We sincerely thank anonymous reviewers whose comments helped to improve the manuscript but also Prof. Liu Shiliang for invaluable suggestions to shape this work. 


\section{References}

Adams, W. M. (2016). The Great Game: Conservation in East Africa 1950-2016. Oryx, 50, 567-568. https://doi.org/10.1017/S0030605316000971

Alec, C. (2012). Conflict-Sensitive Conservation in Nyungwe National Park: Conflict Analysis. Manitoba: The International Institute for Sustainable Development.

Bannari, A., Morin, D., Bonn, F., \& Huete, A. R. (1995). A Review of Vegetation Indices. Remote Sensing Reviews, 13, 95-120. https://doi.org/10.1080/02757259509532298

Barnett, J., \& Dardis, M. (2011). Nyungwe National Park Fire Management Plan, Rwanda. Kigali: Wildlife Conservation Society and Rwanda Development Board.

Brown, M. T., Cohen, M. J., \& Sweeney, S. (2009). Predicting National Sustainability: The Convergence of Energetic, Economic and Environmental Realities. Ecological Modelling, 220, 3424-3438. https://doi.org/10.1016/j.ecolmodel.2009.08.023

Congalton, R. G., \& Green, K. (2008). Assessing the Accuracy of Remotely Sensed Data: Principles and Practices (2nd ed.). Florida: CRC Press.

https://doi.org/10.1201/9781420055139

Cowles, P., Hoffman, C. A., Hakizimana, E., Zerbock, O., McClintock, E., \& Bamwesigye, J. (2013). Evaluation of USAID Investments in Nyungwe National Park. Arlington: ECODIT.

Davies, J. (2012). Conservation and Sustainable Development: Linking Practice and Policy in Eastern Africa. Milton Park: Routledge.

Dewan, A. M., \& Yamaguchi, Y. (2009). Using Remote Sensing and GIS to Detect and Monitor Land Use and Land Cover Change in Dhaka Metropolitan of Bangladesh during 1960-2005. Environmental Monitoring and Assessment, 150, 237-249.

https://doi.org/10.1007/s10661-008-0226-5

Dudley, J. P., Ginsberg, J. R., Plumptre, A. J., Hart, J. A., \& Campos, L. C. (2002). Effects of War and Civil Strife on Wildlife and Wildlife Habitats. Biological Conservation, 16, 319-329. https://doi.org/10.1046/j.1523-1739.2002.00306.x

Earl, S., Fred, C., \& Terry, S. (2001). Outcome Mapping: Building Learning and Reflection into Development Programs. Ottawa: The International Development Research Center.

Fashing, P. J., Mulindahabi, F., Gakima, J.-B., Masozera, M., Mununura, I., Plumptre, A. J., \& Nguyen, N. (2007). Activity and Ranging Patterns of Colobus angolensis Ruwenzorii in Nyungwe Forest, Rwanda: Possible Costs of Large Group Size. International Journal of Primatology, 28, 539-550. https://doi.org/10.1007/s10764-006-9095-3

Fichera, C. R., Modica, G., \& Pollino, M. (2012). Land Cover Classification and Change-Detection Analysis Using Multi-Temporal Remote Sensed Imagery and Landscape Metrics. European Journal of Remote Sensing, 45, 1-18. https://doi.org/10.5721/EuJRS20124501

Field, C. B., Randerson, J. T., \& Malmström, C. M. (1995). Global Net Primary Production: Combing Ecology and Remote Sensing. Remote Sensing of Environment, 51, 74-88. https://doi.org/10.1016/0034-4257(94)00066-V

Fischer, E., Dhetchuvi, J.-B., \& Ntaganda, C. (2003). A New Species of Impatiens (Balsaminaceae) from Nyungwe Forest, Rwanda. Systematics and Geography of Plants. Systematics and Geography of Plants, 73, 91-95.

Forkuo, E. K., \& Frimpong, A. (2012). Analysis of Forest Cover Change Detection. International Journal of Remote Sensing Applications, 2, 82-92.

Gao, Y., Zhou, X., Wang, Q., Wang, C., Zhan, Z., Chen, L., Yan, J., \& Qu, R. (2013). Vegetation Net Primary Productivity and Its Response to Climate Change during 2001-2008 in the Tibetan Plateau. Science of the Total Environment, 444, 356-362. 
https://doi.org/10.1016/j.scitotenv.2012.12.014

Glew, L., \& Hudson, M. D. (2007). Gorillas in the Midst: The Impact of Armed Conflict on the Conservation of Protected Areas in Sub-Saharan Africa. Oryx, 41, 140-150. https://doi.org/10.1017/S0030605307001755

Huang, C., Yang, L., Homer, C., Wylie, B., Vogelman, J., \& DeFelice, T. (2001). At-Satellite Reflectance: A First Order Normalization of Landsat 7 ETM+ Images. Middleton: US Geological Survey, 1-9.

Kanyamibwa, S. (1998). Impact of War on Conservation: Rwandan Environment and Wildlife in Agony. Biodiversity and Conservation, 7, 1399-1406.

https://doi.org/10.1023/A:1008880113990

Kaplin, B. A. (2001). Ranging Behavior of Two Species of Guenons (Cercopithecus lhoesti and $C$. mitis doggetti) in the Nyungwe Forest Reserve, Rwanda. International Journal of Primatology, 22, 521-548. https://doi.org/10.1023/A:1010716001014

Kapos, V., Balmford, A., Aveling, R., Bubb, P., Carey, P., Entwistle, A., Hopkins, J., Mulliken, T., Safford, R., Stattersfield, A., Walpole, M., \& Manica, A. (2008). Calibrating Conservation: New Tools for Measuring Success. Conservation Letters, 1, 155-164. https://doi.org/10.1111/j.1755-263X.2008.00025.x

Lal, M., \& Singh, R. (2000). Carbon Sequestration Potential of Indian Forests. Environmental Monitoring and Assessment, 60, 315-327. https://doi.org/10.1023/A:1006139418804

Li, A., Bian, J., Lei, G., \& Huang, C. (2012). Estimating the Maximal Light Use Efficiency for Different Vegetation through the CASA Model Combined with Time-Series Remote Sensing Data and Ground Measurements. Remote Sensing, 4, 3857-3876. https://doi.org/10.3390/rs4123857

Masozera, M. K. (2002). Socioeconomic Impact Analysis of the Conservation of the Nyungwe Forest Reserve, Rwanda. Gainesville, FL: University of Florida.

Matthew, R., Halle, M., \& Switzer, J. (2002). Conserving the Peace: Resources, Livelihoods and Security. Winnipeg-Manitoba: International Institute for Sustainable Development.

Mau, A. C. (2015). Instantaneous Photosynthetic Response to Temperature of Mature Forest Canopies and Experimentally Warmed Seedlings. Houghton, MI: Michigan Technological University.

Monteith, J. L. (1972). Solar Radition and Productivity in Tropical Ecosystems. Journal of Applied Ecology, 9, 747-766. https://doi.org/10.2307/2401901

Mulindahabi, F., \& Ntare, N. (2013). Biodiversity Research and Monitoring: Nyungwe National Park. Kigali: Wildlife Conservation Society-Rwanda Program.

Mulindahabi, F., Aaron, N., \& Rugerinyange, L. (2011). Nyungwe National Park, Rwanda 5-Year Ranger-Based Ranger Based Monitoring Comparison Report 2006 to 2010. Kigali: Wildlife Conservation Society and Rwanda Development Board.

Myeong, S., Nowak, D. J., \& Duggin, M. J. (2006). A Temporal Analysis of Urban Forest Carbon Storage using Remote Sensing. Remote Sensing of Environment, 101, 277-282. https://doi.org/10.1016/j.rse.2005.12.001

Myers, N., Mittermeier, R. A., Mittermeier, C. G., da Fonseca, G. A. B., \& Kent, J. (2000). Biodiversity Hotspots for Conservation Priorities. Nature, 403, 853-858.

https://doi.org/10.1038/35002501

Myneni, R. B., \& Williams, D. L. (1994). On the Relationship between FAPAR and NDVI. Remote Sensing of Environment, 49, 200-211. https://doi.org/10.1016/0034-4257(94)90016-7

NCEP (2016). The National Centers for Environmental Prediction (NCEP) Global 
Weather Data for SWAT. http://globalweather.tamu.edu/home/view/33950

Okwaare, S., \& Hargreaves, S. (2009). Critical Stories of Change: The Benet Community of Uganda. Johannesburg: ActionAid.

Plumptre, A. J., Helga, R., Maryke, G., Ian, M., Kayitare, A., Barakabuye, N., Asuma, S., Sivha, M., \& Namara, A. (2004). Socioeconomic Status of People Living near Protected Areas in the Central Albertine Rift. New York, NY: Albertine Rift Technical Reports.

Plumptre, A. J., Masozera, M., Fashing, P. J., McNeilage, A., Ewango, C., Kaplin, B. A., \& Liengola, I. (2002). Biodiversity Surveys of the Nyungwe Forest Reserve (No. 9). Working Paper, New York, NY: WCS.

Potter, C. S., Randerson, J. T., Field, C. B., Matson, P. A., Vitousek, P. M., Mooney, H. A., \& Klooster, S. A. (1993). Terrestrial Ecosystem Production: A Process Model Based on Global Satellite and Surface Data. Global Biogeochemical Cycles, 7, 811-841. https://doi.org/10.1029/93GB02725

Price, S. V. (2003). War and Tropical Forests: Conservation in Areas of Armed Conflict. Food Products Press.

Reusing, M. (2000). Change Detection of Natural High Forests in Ethiopia using Remote Sensing and GIS Techniques. The International Archives of the Photogrammetry, Remote Sensing, 33, 1253-1258.

Rutebuka, E., Nsabimana, D., \& Gross-camp, N. D. (2012). Evaluation of Community Based Conservation around Protected Areas in Rwanda, Nyungwe National Park. In Student Conference on Conservation Science (pp. 1-8). USA, NY.

Seimon, A. (2012). Climatology and Potential Climate Change Impacts in the Nyungwe Forest National Park, Rwanda. Technical Report, New York, NY: WCS.

Selener, D., Purdy, C., \& Zapata, G. (1996). Documenting, Evaluating and Learning from our Development Projects: A Participatory Systematization Workbook. New York, NY: International Institute of Rural Reconstruction.

Sims, D. A., Luo, H., Hastings, S., Oechel, W. C., Rahman, A. F., \& Gamon, J. (2006). Parallel Adjustments in Vegetation Greenness and Ecosystem CO2 Exchange in Response to Drought in a Southern California Chaparral Ecosystem. Remote Sensing of Environment, 103, 289-303. https://doi.org/10.1016/j.rse.2005.01.020

Singh, A. (1989). Review Article Digital Change Detection Techniques using Remotely-Sensed Data. International Journal of Remote Sensing, 10, 989-1003.

https://doi.org/10.1080/01431168908903939

Turner, D. P., Gower, S. T., Cohen, W. B., Gregory, M., \& Maiersperger, T. K. (2002). Effects of Spatial Variability in Light Use Efficiency on Satellite-Based NPP Monitoring. Remote Sensing of Environment, 80, 397-405. https://doi.org/10.1016/S0034-4257(01)00319-4

Uddin, S., Ghadban, A. N., Dousari, A., Murad, M., \& Shamroukh, D. (2010). A Remote Sensing Classification for Land-Cover Changes and Micro-Climate in Kuwait. International Journal of Sustainable Development and Planning, 5, 367-377. https://doi.org/10.2495/SDP-V5-N4-367-377

USGS (2016). Global Visualization Viewer USGS Global Visualization Viewer [WWW Document]. http://glovis.usgs.gov/

Vårhammar, A., Wallin, G., McLean, C. M., Dusenge, M. E., Medlyn, B. E., Hasper, T. B., Nsabimana, D., \& Uddling, J. (2015). Photosynthetic Temperature Responses of Tree Species in Rwanda: Evidence of Pronounced Negative Effects of High Temperature in Montane Rainforest Climax Species. New Phytologist Journal, 206, 1000-1012. https://doi.org/10.1111/nph.13291 
Washington, H., Baillie, J., Waterman, C., \& Milner-Gulland, E. (2015). A Framework for Evaluating the Effectiveness of Conservation Attention at the Species Level. Oryx, 49, 481-491. https://doi.org/10.1017/S0030605314000763

Webber, B. (2013). Sustaining Biodiversity Conservation in and around Nyungwe National Park: Looking forward through the Past: Progress, Challenges, and Lessons Learned by WCS in Nyungwe National Park, Rwanda 1988-2013. Kigali: United States Agency for International Development (USAID).

Wenquan, Z., Yaozhong, P., Hao, H., Deyong, Y., \& Haibo, H. (2006). Simulation of Maximum Light Use Efficiency for Some Typical Vegetation Types in China. Chinese Science Bulletin, 51, 457-463. https://doi.org/10.1007/s11434-006-0457-1

Wilder, L., \& Walpole, M. (2008). Measuring Social Impacts in Conservation: Experience of Using the Most Significant Change Method. Oryx, 42, 1-10. https://doi.org/10.1017/S0030605307000671

Woodcock, C. E., Macomber, S. A., Pax-Lenney, M., \& Cohen, W. B. (2001). Monitoring Large Areas for Forest Change using Landsat: Generalization across Space, Time and Landsat Sensors. Remote Sensing of Environment, 78, 194-203. https://doi.org/10.1016/S0034-4257(01)00259-0

Zhao, H., Chen, X., \& Area, A. S. (2005). Use of Normalized Difference Bareness Index in Quickly Mapping Bare Areas from TM/ETM+. In Geoscience and Remote Sensing Symposium (pp. 1666-1668). Seoul: IEEE. 